\title{
Fuzzy Approach for the Formation of an Optimal Portfolio of Strategic Projects to Achieve Regional Development Targets in the Digital Economy
}

\author{
Lev Mazelis $^{1}$, Kirill Lavrenyuk ${ }^{2 *}$, Andrey Krasko ${ }^{1}$ \\ ${ }^{1}$ Laboratory Department of Mathematics and Modelling, Vladivostok State University of Economics and \\ Service, st. Gogol 41, Vladivostok 690014, Russia \\ ${ }^{2}$ Human Resources Directorate, RT-Techpriemka, Electric lane 1/12, Moscow 123557, Russia
}

\begin{abstract}
This study was performed as part of an essential task of accumulating and developing regional human capital in the digital economy. In this age of uncertainties, risks, and scarcity of resources, regional leadership faces the task of the optimal allocation of available financial resources among strategic projects that directly or indirectly affect the development of regional human capital. The aim of this study was to develop and test the economic and mathematical method of forming the optimal portfolio of strategic projects to maximize progress towards achieving the target values of key indicators of regional development through the development of human capital using a fuzzy approach. A fuzzy model is proposed, and its objective function is an integrated index that takes into account the degrees of achievement of strategic indicators of the social and economic development of a region. The information base of the study is composed of statistical data from official information resources. The model is a fuzzy mathematical programming problem in which the uncertainty and lack of information are modeled using a fuzzy approach. The variables used for the optimization are the Boolean variables of the inclusion of a project in a particular investment area at a certain point in time in a project portfolio. The transition from a fuzzy optimization problem to a crisp one is performed by setting confidence levels for the objective function and constraints. The choice of a certain confidence level allows, to some extent, one to take into account the uncertainty, which in turn affects the structure of the investment allocation. For the Primorsky Region, an example of the formation of an optimal portfolio of projects is considered by each year of a given planning period, which allows for maximum progress towards achieving the targets of development for the region.
\end{abstract}

Keywords: Economic and mathematical model; Fuzzy logic; Project portfolio optimization; Regional human capital; Social and economic development

\section{Introduction}

Currently, regions operate in the context of the on-going digital transformation of the economy and social environment. The penetration of cutting-edge technologies into the environment of human functioning produces new innovative businesses and products and results in the automation and digitalization of business processes (Berawi, 2019). However, the integration of technological innovations into everyday life also demands new requirements for the quality and pace of the development of human capital (Santoso et al., 2019). The modification of human capital is associated with the rapid emergence of new digital competencies and their continual development. In turn, public authorities can

*Corresponding author's email: k.lavrenyuk@rt-techpriemka.ru, Tel.: +7-902-051-07-76 doi: 10.14716/ijtech.v11i6.4433 
contribute to the development of human capital through the implementation of projects that are aimed at creating favorable conditions for organizing educational processes that, for example, meet the requirements of employers, deliver quality medical care (Berawi, 2020), etc. This leads to the need to address the issue of the optimal allocation of resources that are available in a region among such projects to obtain a maximum effect.

Currently, there is ongoing research on the problems of the development of human capital at various levels. The research data can be logically structured into three groups.

Group I includes studies that focus on the quantitative assessment of human capital. One of the most popular tools for assessing human capital is the human development index (UNDP, 2019). Gurban (2015) presents the value of human capital by subjects of the Russian Federation as the average of the following components: demography, education, employment, science, and social culture. Lim et al. (2018) made a systematic analysis of human capital for 195 countries and regions for the period 1990-2016. There are many studies devoted to the subject of the quantitative assessment of human capital in different geographical areas, for example, in the U.S. (Christian, 2014) and China (Li et al., 2016).

Group II includes studies that focus on assessing the impact of the investment process on human capital. For example, Pelinescu (2014) considers the impact of investments aimed at ensuring the birth rate, creating a training system for highly qualified specialists and the social welfare of the population, and developing a region's human capital. Percoco (2016) analyses the impact of changes in the secondary and higher education systems in a country on the change in the human capital development index. In addition, Soubjaki (2017) analyses the relationship between negative contributors to the health status of the population and human capital. Fraumeni et al. (2019) proposes a new complex measure of human capital investment.

Group III includes studies that focus on the assessment of the impact of human capital on the development of a specific social and economic system. For example, McDonald (2019) describes the positive impact of investment in human capital of the U.S. defense sector on the economic growth of the states and the country as a whole. Olopade et al. (2019) analyses the impact of human capital development on poverty reduction in terms of long-term economic growth. Teixeira and Queirós (2016) note that in 1960-2011, the investment in human capital and the dynamics of production specialization were critical economic growth factors for developed countries. Zallé (2019) indicates clear feedback between the rate of exploitation of natural resources and the level of development of human capital.

The analysis of referenced works allows us to discuss the lack of tools that would allow the reasonable formation of an optimal set of regional strategic projects that directly or indirectly affect the development of regional human capital to maximize progress towards achieving the targets of the development of a region. When forming an optimal project portfolio, the current parameters and specifics of the region, the planning period, and available resource constraints should be taken into account. Special focus should be directed toward the consideration of environmental uncertainties and incomplete information. Aras et al. (2008) consider the use of fuzzy logic for modeling social and economic processes. The fuzzy set approach is viewed as a promising direction, which allows the modeling of uncertainties of verbal expert estimates of model parameters and potential risks by representing parameters and functional dependencies in the form of fuzzy numbers (Carlsson et al., 2007). Fuzzy problems require special solution methods. However, the lack of examples of implementations of the proposed methods and approaches in real cases of the formation of time-variant project portfolios presents considerable difficulties in their further use in optimization models. Fuzzy optimization models with fuzzy objective functions and constraints allow the results to vary when setting various exogenously established confidence levels (Anshin, 2015).

Thus, the aim of this study was to develop an economic and mathematical method of 
forming the optimal portfolio of strategic projects to achieve the target values of key indicators of regional development through the development of its human capital in a fuzzy setting.

\section{Methods}

Mazelis et al. (2018) describe a conceptual model for the development of regional human capital. They also propose an economic and mathematical model, which is the formalization of the main part of the conceptual model in the form of a mathematical programming problem in a crisp setting.

The current study, which is a continuation of the work described in Mazelis et al. (2020), extends the model considered therein; specifically, the model represents investments as a list of federal and regional projects and considers the modeling of uncertainties using a fuzzy-plural representation of parameter estimates of the developed econometric dependencies.

We will now briefly describe the key points of the crisp model.

The objective function of the model is

$$
\operatorname{ISE}_{n}(T)=\sum_{p=1}^{P} \frac{w_{p n}(T)}{\widetilde{w}_{p n}} \cdot v_{p n} \rightarrow \max , \sum_{p=1}^{P} v_{p n}=1,
$$

where $w_{p n}(t)$ and $\widetilde{w}_{p n}$ are the value and the target value, respectively, of the $p$-th indicator of the social and economic development of the $n$-th region at time $t ; v_{p n}$ is the coefficient of importance of the $p$-th indicator of the social and economic development for the $n$-th region; $p$ is the number of the indicator that describes the social and economic development of the region, $p=1,2, \ldots, P$; $n$ is the number of the region, $n=1,2, \ldots, \mathrm{N}$; and $T$ is the planning period. Of note, a set of development indicators $\left(w_{1 n}(t), \ldots, w_{P n}(t)\right)$ is defined for all regions and is described by Mazelis et al. (2020).

To find $w_{p n}(t)$, the following dependencies are developed according to panel data:

$$
w_{p n}(t)=f_{p}\left(w_{p n}(t-1), R C X_{1 n}(t-1), \ldots, R C X_{K n}(t-1)\right),
$$

where $R C X_{k n}(t)$ is the value of the $k$-th principal component of human capital, and $k$ is the number of the principal component, $k=1,2, \ldots, K$.

The values of $R C X_{k n}(t)$ are calculated on the basis of the values of the indicators of the development of the human capital of the region $\left(x_{1 n}(t), \ldots, x_{M n}(t)\right)$ (the method is described in Mazelis et al. (2018); the indicators are described in Mazelis et al. (2020), where $x_{m n}(t)$ is the value of the $m$-th indicator of the development of human capital of the $n$-th region at time $t$. To determine $R C X_{k n}(t)$, the following dependencies are developed according to panel data:

$$
R C X_{k n}(t)=g_{k}\left(\begin{array}{c}
R C X_{k n}(t-1), z_{1 n}(t-1), \ldots, z_{R n}(t-1) \\
z_{1 n}(t-2), \ldots, z_{R n}(t-2), z_{1 n}(t-3), \ldots, z_{R n}(t-3)
\end{array}\right),
$$

where $z_{r n}(t)$ is the amount of finances allocated to the $r$-th investment area in the $n$-th region at time $t$.

Mazelis et al. (2020) identifies 12 investment areas: national issues ( $r=1)$, national defense ( $r=2)$, national security and law enforcement $(r=3)$, national economy $(r=4)$, housing and utilities $(r=5)$, environmental protection $(r=6)$, culture and cinematography $(r=7)$, social policy $(r=8)$, mass media $(r=9)$, education $(r=10)$, healthcare $(r=11)$, and physical education and sports $(r=12)$.

Unlike Mazelis et al. (2020), we assumed that $z_{r n}(t)$ consisted of four components: 


$$
z_{r n}(t)=z_{r n}^{1.0}(t)+z_{r n}^{2.0}(t)+z_{r n}^{3.0}(t)+z_{r n}^{4.0}(t)
$$

where $z_{r n}^{1.0}(t), z_{r n}^{2.0}(t), z_{r n}^{3.0}(t)$, and $z_{r n}^{4.0}(t)$ are the amounts of finances allocated from the federal budget, the regional budget, the total budget of companies, and the cash income of the population, respectively, and directed to the $r$-th investment area in the $n$-th region at time $t$.

Of note, investments can be divided into process investments and project investments. Project investments can be further subdivided into one time and cyclic. Investments in onetime projects can be instantaneous or divided over several years.

Now, we will consider each component in more detail.

The values of $z_{r n}^{1.0}(t)$ are determined on the basis of the analysis of ongoing activities as part of national projects.

The values of $z_{r n}^{2.0}(t)$ are determined on the basis of the analysis of the law "On the Regional Budget" as follows:

$$
z_{r n}^{2.0}(t)=\alpha_{r n} \cdot \beta_{r n} \cdot z_{r n}^{2.0}(t-1)+\sum_{i=1}^{I_{r}}\left(y_{i r n}(t) \cdot C_{i r n}^{2.0}(t)\right)
$$

where $\alpha_{r n}$ is the coefficient of change in the amount of finances allocated from the budget of the $n$-th region and directed to the $r$-th investment area, $\alpha_{r n} \geq 0 ; \beta_{r n}$ is the share of process investments in the total amount of finances allocated from the budget of the $n$-th region and directed to the $r$-th investment area, $0 \leq \beta_{r n} \leq 1 ; y_{i r n}(t)$ is the variable of inclusion of the $i$-th project in the regional project portfolio that assumes the value 0 (if the project is not included in the portfolio) or 1 (if the project is included in the portfolio); $C_{i r n}^{2.0}(t)$ is the amount of finances allocated from the budget of the $n$-th region and purposed for the implementation of the $i$-th project. Of note, if a decision is made to include a onetime project in the portfolio at time $t$ and if the investments of this project are divided into several years (e.g., $t, t+1$, and $t+2$ ), the project's investments for subsequent years are also reflected in the portfolio.

The values of $z_{r n}^{3.0}(t)$ are determined on the basis of the results of surveys of companies on the amount and structure of investments allocated for the development of human capital in terms of their own employees using the following formula:

$$
z_{r n}^{3.0}(t)=\varphi_{r n} \cdot \gamma_{r n} \cdot z_{r n}^{3.0}(t-1)+\sum_{i=1}^{I_{r}}\left(y_{i r n}(t) \cdot C_{i r n}^{3.1}(t)\right)+\sum_{i=1}^{J_{r}} C_{j r n}^{3.2}(t),
$$

where $\varphi_{r n}$ and $\gamma_{r n}$ are the coefficient of change in the volume of financial resources allocated from the total budget of companies in the region and the share of process investments in them, respectively, and $\varphi_{r n} \geq 0$ and $0 \leq \gamma_{r n} \leq 1 ; C_{i r n}^{3.1}(t)$ and $C_{j r n}^{3.2}(t)$ are the amount of funds allocated from the total budget of the region's companies and directed to the implementation of the $i$-th regional and $j$-th private projects (without co-financing), respectively, and the projects are within the $r$-th area of investment in time $t$.

The values of $z_{r n}^{4.0}(t)$ are determined on the basis of the projected values $H_{r n}(t)$ under the developed econometric model on the basis of the statistical data on consumer spending of the population as follows:

$$
z_{r n}^{4.0}(t)=D_{n}(t) \cdot H_{r n}(t),
$$

where $D_{n}(t)$ is the population of the $n$-th region at time $t$; and $H_{r n}(t)$ is the average cost for the $r$-th investment area per person living in the territory of the $n$-th region at time $t$.

Of note, the investments at the regional level, which can be managed to maximize their 
effect, are financial resources allocated from the regional budget and purposed for the implementation of strategic regional projects. Therefore, the model uses the Boolean variables $y_{i r n}(t)$ as optimization variables.

The econometric dependencies (Equation 2) and (Equation 3) used in the model have a considerable uncertainty associated with the reliability of the estimates of the numerical coefficients of each dependence. To model this uncertainty, we use the fuzzy-plural approach: we assume that each coefficient of the developed econometric dependence is a fuzzy triangular number $\left(a_{1}, a_{2}, a_{3}\right)$, where $a_{2}$ is the coefficient in the model, $a_{2}-a_{1}=$ $a_{3}-a_{2}$, and it matches the value of the confidence interval for this coefficient at a level of 0.95 .

For example, the functional dependence $w_{1}(t)$ for the cluster that includes the Primorsky Region is as follows:

$$
w_{1}(t)=\left(\begin{array}{c}
0.15+0.84 \cdot w_{1}(t-1)-0.22 \cdot R C X_{1}(t-1)+0.28 \cdot R C X_{2}(t-1)- \\
-0.46 \cdot R C X_{3}(t-1)+0.14 \cdot R C X_{4}(t-1)+0.09 \cdot R C X_{5}(t-1)
\end{array}\right)
$$

Thus, the coefficient at $R C X_{2}(t-1)$ is equal to 0.28 . Therefore, the coefficients $a_{1}$ and $a_{3}$ can take values of 0.23 and 0.33 , respectively.

The model restrictions are as follows:

- The amount of finances allocated from the budget of the $n$-th region and purposed for the direct or indirect development of its human capital at time $t$ is restricted by the total cost $R_{n}(t)$, such that

$$
\sum_{r=1}^{12} z_{r n}^{2.0}(t) \leq R_{n}(t)
$$

- The annual growth rates of investment from the regional budget for each investment area have lower $\bar{a}=\left(a_{1}, \ldots, a_{12}\right)$ and upper $\bar{b}=\left(b_{1}, \ldots, b_{12}\right)$ restrictions, such that

$$
a_{r} \leq \frac{z_{r n}^{2.0}(t)}{z_{r n}^{2.0}(t-1)} \leq b_{r}
$$

- If one period in the model is equal to one year, most indicators of the development of human capital of the region for a given period cannot change considerably; in other words, the relative gain of the principal components has lower $\bar{c}=$ $\left(c_{1}, \ldots, c_{K}\right)$ and upper $\bar{d}=\left(d_{1}, \ldots, d_{K}\right)$ restrictions, such that

$$
c_{k} \leq \frac{R C X_{k n}(t+1)-R C X_{k n}(t)}{R C X_{k n}(t)} \leq d_{k} ;
$$

- The degrees of achievement of target values at time $T$ should not differ considerably from the target values. In other words, the deviations of the values of the regional development indicators from the target values have lower $\bar{e}=$ $\left(e_{1}, \ldots, e_{P}\right)$ and upper $\bar{f}=\left(f_{1}, \ldots, f_{P}\right)$ restrictions, such that

$$
e_{p} \leq \frac{w_{p n}(T)}{\widetilde{w}_{p n}} \leq f_{p}
$$

The second level of uncertainties in the model is associated with the need to set the parameters of dependencies (Equation 5) and (Equation 6) and restrictions (Equation 10) through (Equation 12). The model parameter values $v_{p n}, \alpha_{r n}, \beta_{r n}, \varphi_{r n}, \gamma_{r n}, a_{r}, b_{r}, c_{k}, d_{k}, e_{p}$, and $f_{p}$ are determined from expert estimates. The assignment of given values in the form of crisp numbers is challenging for an expert. It is easier for an expert to formulate these 
values in the form of verbal assessments by taking into account personal views and feelings. For an expert, one way to simplify the task is to use a fuzzy set approach. Therefore, we use verbal estimates converted into fuzzy triangular numbers as estimates for these parameters.

For example, for the linguistic variable $\beta=<$ share of process investments in the total amount of finance $>$, the term set can be written as $V(\beta)=$ approximately $0 \%$; approximately $25 \%$; approximately 50\%; approximately 75\%; approximately 100\%\}. The membership functions are given in the form of fuzzy numbers as follows:

- $W($ approximately $0 \%)=\{0 ; 0 ; 0.25\}$;

- $W($ approximately $50 \%)=\{0.25 ; 0.5 ; 0.75\}$;

- $W($ approximately $100 \%)=\{0.75 ; 1 ; 1\}$.

For other model parameters, fuzziness is determined in a similar manner.

Of note, an expert survey is conducted to determine the values of model parameters; the survey is based on the opinions of independent experts. The consolidation of expert opinions is performed using the following formula:

$$
\bar{r}=\sum_{q=1}^{Q} r^{q} \cdot v\left(s^{q}\right), v\left(s^{q}\right)=\frac{s^{q}}{\sum_{q=1}^{Q} s^{q}},
$$

where $r^{q}$ is the parameter estimate given by the $q$-th expert; $v\left(s^{q}\right)$ is the respondent's importance function; $s^{q}$ is the estimate of the competence level of the $q$-th expert in assessing the value of parameter $r$; and $Q$ is the number of experts surveyed.

To determine the coefficients of importance of the social and economic development of the region, it is necessary to normalize the estimates as follows: divide the consolidated importance estimate of the $m$-th indicator by the sum of all the consolidated importance estimates of the indicators.

Thus, it is proposed that the formation of an optimal portfolio of strategic projects should be performed using the following optimization model:

$$
\left\{\begin{array}{c}
I S E_{n}(T)=\sum_{p=1}^{P} \frac{w_{p n}(T)}{\widetilde{w}_{p n}} \cdot v_{p n} \rightarrow \max , \sum_{p=1}^{P} v_{p n}=1, n=1, \ldots, N, t=0, \ldots, T, \\
w_{p n}(t+1)=f_{p}\left(w_{p n}(t), R C X_{1 n}(t), \ldots, R C X_{K n}(t)\right), p=1, \ldots, P, \\
R C X_{k n}(t)=g_{k}\left(\begin{array}{c}
R C X_{k n}(t-1), z_{1 n}(t-1), \ldots, z_{R n}(t-1), \\
z_{1 n}(t-2), \ldots, z_{R n}(t-2), z_{1 n}(t-3), \ldots, z_{R n}(t-3)
\end{array}\right), k=1, \ldots, K, \\
z_{r n}(t)=z_{r n}^{1.0}(t)+z_{r n}^{2.0}(t)+z_{r n}^{3.0}(t)+z_{r n}^{4.0}(t), r=1, \ldots, 12, \\
z_{r n}^{2.0}(t)=\alpha_{r n} \cdot \beta_{r n} \cdot z_{r n}^{2.0}(t-1)+\sum_{i=1}^{I_{r}}\left(y_{i r n}(t) \cdot C_{i r n}^{2.0}(t)\right), i=1, \ldots, I_{r}, \\
z_{r n}^{3.0}(t)=\left(\begin{array}{c}
I_{r} \\
\left.\varphi_{r n} \cdot \gamma_{r n} \cdot z_{r n}^{3.0}(t-1)+\sum_{i=1}^{3.0}\left(y_{i r n}(t) \cdot C_{i r n}^{3.1}(t)\right)+\sum_{i=1}^{4.0}(t)=C_{j r n}^{3.2}(t)\right), j=1, \ldots, J_{r},
\end{array}\right), H_{r n}(t), \sum_{r=1}^{12} z_{r n}^{2.0}(t) \leq R_{n}(t), \\
a_{r} \leq \frac{z_{r n}^{2.0}(t)}{z_{r n}^{2.0}(t-1)} \leq b_{r}, c_{k} \leq \frac{R C X_{k n}(t+1)-R C X_{k n}(t)}{R C X_{k n}(t)} \leq d_{k}, e_{p} \leq \frac{w_{p n}(T)}{\widetilde{w}_{p n}} \leq f_{p} .
\end{array}\right.
$$

The proposed model is a fuzzy programming problem because most of the dependency coefficients that determine the objective function and the restriction parameters are fuzzy 
numbers. Therefore, it is necessary to develop a method to identify a solution to the fuzzy problem of forming an optimal portfolio of regional strategic projects. We will use the approach referred to in Anshin (2015) and Wang et al. (2007). The idea of the approach is to reduce the fuzzy optimization model to a crisp one by converting fuzzy inequalities for the objective function and restrictions into crisp ones at given confidence levels.

We set the confidence levels $\lambda_{I S E}, \lambda_{R}, \lambda_{a}, \lambda_{b}, \lambda_{c}, \lambda_{d}, \lambda_{e}$, and $\lambda_{f}$ for the objective function and restrictions, respectively. We have the following system of relations:

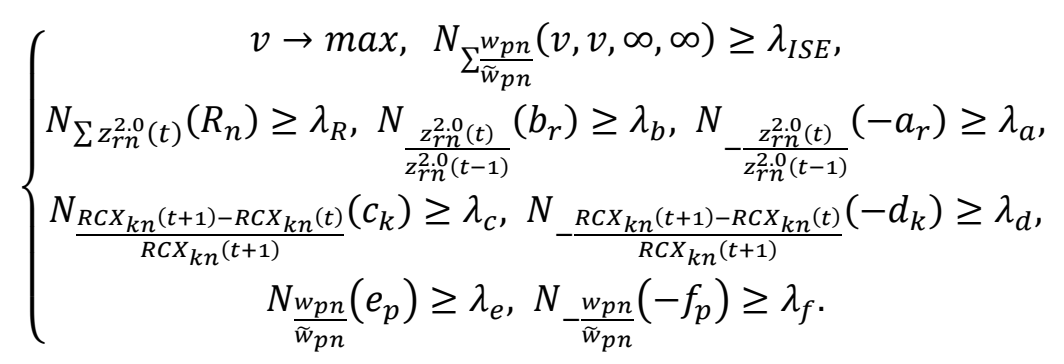

Here, $N_{A}(B)>\lambda$ means that number $A$ satisfies restriction $B$ with confidence level $\lambda$.

This condition is equivalent to the following inequality:

$$
\min _{x} \max \left(1-\mu_{A}(x), \mu_{B}(x)\right)>\lambda,
$$

where $\mu_{Y}(x)$ is the membership function of the fuzzy number $Y$.

Specifically, let us assume that the total amount of finances allocated from the budget of the $n$-th region to all the investment areas at time $t$ is a trapezoidal fuzzy number $\sum z_{r n}^{2.0}(t)=\left(z_{1}, z_{2}, z_{3}, z_{4}\right)$, and the upper restriction for the total amount of budget expenditures has a fuzzy representation $R_{n}(t)=\left(0,0, v_{3}, v_{4}\right)$. Then, the fuzzy restriction $N_{\sum z_{r n}^{2.0}(t)}\left(R_{n}\right) \geq \lambda_{R}$ is equivalent to

$$
\left[\left(1-\lambda_{R}\right) \cdot z_{3}+\lambda_{R} \cdot z_{4}\right] \leq \lambda_{R} \cdot v_{3}+\left(1-\lambda_{R}\right) \cdot v_{3} .
$$

Similarly, fuzzy inequalities are represented in the form of crisp inequalities. Thus, we arrive at the crisp problem of Boolean programming. To solve this problem, it is necessary to use typical numerical optimization software packages, for example, the evolutionary algorithm in the "Solver" add-in package of MS Excel or the branch-and-bound method.

\section{Results and Discussion}

The model for the formation of an optimal portfolio of regional projects described above can be applied under real conditions. Let us consider an example of the formation of a project portfolio that allows for the maximum possible progress towards achieving the targets of the social and economic development of the region on the basis of the rapid development of human capital for the Primorsky Region.

Statistical data from open sources on investment volumes by investment areas, indicators of human capital, and social and economic development for the regions of the Russian Federation for 2011-2018 were used as reference data. Mazelis et al. (2018) describe the clustering of regions by human capital performance. Of note, the Primorsky Region was added to the "small" cluster.

For this cluster, the principal components of human capital development were developed using the Kaiser criterion.

To obtain dependencies (Equation 2) and (Equation 3), the best-subject method was used to develop panel data models with deterministic spatial effects. In addition, the 
obtained regression coefficients for dependencies (Equation 2) and (Equation 3) were converted into fuzzy triangular numbers using the method described earlier.

For the selected region, we considered the formation of a portfolio of strategic projects with a planning period $T=3$. The targets of social and economic development established by the administration of the region are shown in Table 1.

Table 1 Targets of social and economic development of the Primorsky Region

\begin{tabular}{llcc}
\hline & Indicator & Actual & Target \\
\hline 1) & Share of employed population in labor force & 0.94 & 0.98 \\
\hline 2) & Per capita cash income correlated with the minimum subsistence level & 2.6 & 2.95 \\
\hline 3) & Amount of consumption expenditures per capita per month & 22,385 & 26,822 \\
\hline 4) & Share of consumption expenditures in the total income of the population & 69.1 & 71.74 \\
\hline 5) & GRP per capita & 382,586 & 457,453 \\
\hline 6) & Fixed assets value at the end of the year at the gross book value per capita & $1,620,423$ & $1,863,486$ \\
\hline 7) Fixed capital expenditures per capita at actual prices & 64,120 & 76,362 \\
\hline 8) Industrial production index & 97.80 & 104.90 \\
\hline 9) Commissioning of residential and non-residential buildings per capita & 0.37 & 0.55 \\
\hline 10) Aggregate turnover of retail trade, catering, and paid services per capita & 260,688 & 301,133 \\
11) Proportion of break-even organizations, as a percentage of the total & 69.20 & 79.30 \\
\hline & number of organizations & 58,512 & 67,289 \\
\hline 12) Consolidated budget revenues per capita & 5
\end{tabular}

Now, we consider two scenarios:

1) The optimization scenario, in which the structure of the investments allocated for the implementation of projects is calculated according to the model;

2) The inertial scenario, in which the structure of the investments allocated for the implementation of regional projects is obtained from the draft budget of the Primorsky Region (both scenarios have the same total investment by year).

The total number of projects under consideration, which could be implemented within three years, was 264. The total investment from the regional budget that was necessary for the implementation of all the projects within the first year was 130.81 billion RUB (the required total investment for three years was 266.36 billion RUB).

However, the restrictions on the amount of investment of budgetary funds of the Primorsky Region by year were as follows: in the first year, 45 billion RUB; in the second year, 32 billion RUB; and in the third year, 29 billion RUB.

The expert survey yielded verbal estimates of the input parameters and model restrictions, which were converted into fuzzy numbers.

The following are the results of the formation of the optimal portfolio of strategic projects using the model with the above-mentioned restrictions of the planning period. To identify a solution to the model using the above-mentioned approach, the fuzzy mathematical programming problem was reduced to a crisp one by converting the fuzzy inequalities for the objective function and constraints into crisp ones at given confidence levels. For this example, the confidence level was 0.95 . The crisp problem was solved numerically using the Solver add-in for Microsoft Excel. Table 2 shows the optimal project portfolio for the Primorsky Region by year.

Of note, the implementation period for the number of projects was two years. This means that the decision-making on the implementation of such projects at time $t$ should also take into account the existing financial needs at time $t+1$. 
Table 2 Portfolio of regional strategic projects

\begin{tabular}{|c|c|c|c|c|c|c|}
\hline \multirow{2}{*}{$\begin{array}{l}\text { Investment } \\
\text { area }\end{array}$} & \multicolumn{3}{|c|}{$\begin{array}{l}\text { Number of one-time projects / Costs of } \\
\text { implementing one-time projects, BRUB }\end{array}$} & \multicolumn{3}{|c|}{$\begin{array}{l}\text { Number of cyclic projects / Costs of } \\
\text { implementing cyclic projects, BRUB }\end{array}$} \\
\hline & $t=1$ & $t=2$ & $t=3$ & $t=1$ & $t=2$ & $t=3$ \\
\hline 1 & $0 / 0$ & $0 / 0$ & $0 / 0$ & $2 / 0.57$ & $1 / 0.75$ & $3 / 1.99$ \\
\hline 2 & $0 / 0$ & $0 / 0$ & $0 / 0$ & $0 / 0$ & $0 / 0$ & $0 / 0$ \\
\hline 3 & $0 / 0$ & $0 / 0$ & $0 / 0$ & $2 / 0.79$ & $2 / 0.79$ & $3 / 1.27$ \\
\hline 4 & $6 / 4.38$ & $0 / 2.01$ & $0 / 0$ & $6 / 5.24$ & $4 / 1.76$ & $0 / 0$ \\
\hline 5 & $0 / 0$ & 4/3.89 & $2 / 2.48$ & $1 / 0.37$ & $2 / 0.91$ & $3 / 1.99$ \\
\hline 6 & $1 / 1.40$ & $4 / 2.57$ & $1 / 2.28$ & $2 / 1.41$ & $1 / 0.64$ & $4 / 3.19$ \\
\hline 7 & $0 / 0$ & $0 / 0$ & $0 / 0$ & $2 / 1.42$ & $2 / 0.90$ & $4 / 2.87$ \\
\hline 8 & $5 / 3.30$ & $1 / 2.96$ & $0 / 0$ & $2 / 2.70$ & $2 / 1.65$ & $3 / 2.19$ \\
\hline 9 & $0 / 0$ & $0 / 0$ & $0 / 0$ & $1 / 1.25$ & $1 / 0.39$ & $3 / 2.31$ \\
\hline 10 & $6 / 4.68$ & $0 / 2.11$ & $0 / 0$ & $6 / 5.64$ & $5 / 2.64$ & $3 / 0.38$ \\
\hline 11 & $4 / 1.92$ & $2 / 2.50$ & $0 / 2.00$ & $6 / 5.60$ & $2 / 1.60$ & $3 / 2.15$ \\
\hline 12 & $2 / 1.33$ & $2 / 2.29$ & $2 / 2.46$ & $3 / 2.98$ & $2 / 1.33$ & $2 / 1.33$ \\
\hline
\end{tabular}

Thus, it is recommended that in the first year of project implementation, the largest amount of investment from the regional budget should be allocated for education ( 10.23 billion RUB, or $22 \%$ of the total investment) and national economy ( 9.62 billion RUB or $21 \%$ of the total investment); in the second year, investments will be allocated more evenly among projects. It is recommended that 4.80 billion RUB (or $15 \%$ ) should be allocated for housing and utilities; 4.75 billion RUB (or 15\%) for education; 4.61 billion RUB (or 15\%) for social policy; and 4.10 billion RUB (or 14\%) for healthcare. In the third year, a uniform distribution structure is also maintained. Of note, investments in the national economy are performed only in the first two years. In the future, it is no longer expedient to invest in the national economy in terms of impact on indicators of social and economic development. A similar situation exists for investing in education. Figure 1 shows a comparative graph of the investment structure over three years for both scenarios and the result of achieving the targets of social and economic development of the Primorsky Region for both the optimization and inertial (calculated directly according to the model) scenarios.

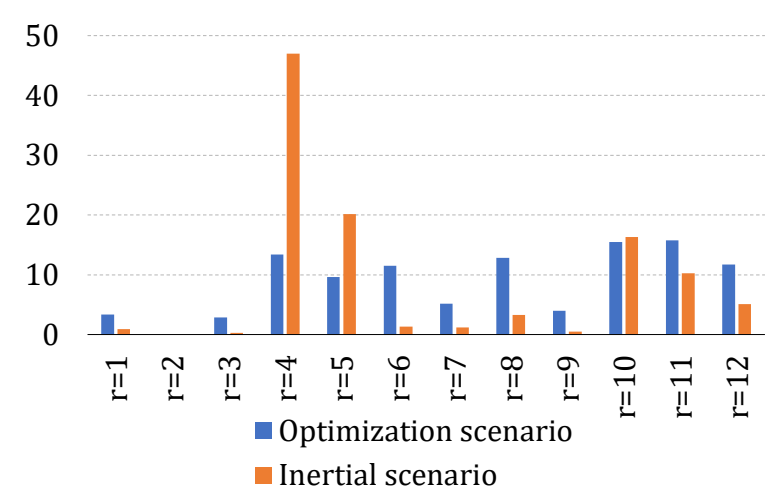

(a)

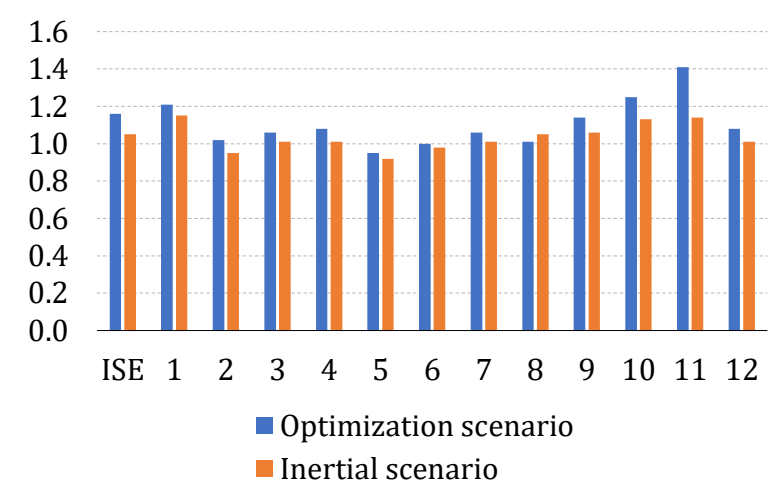

(b)

Figure 1 (a) Comparative graph of investment volumes under inertial and optimization scenarios; (b) Degrees of achievement of indicators of social and economic development of the Primorsky Region under optimization and inertial scenarios

The analysis of the data shown in Figure 1a indicates that the optimization scenario offers a more uniform investment structure. However, in the inertial scenario, the 
predominant investment area is the national economy, for which the planned allocation is more than $44 \%$ of the total regional budget investments over three years.

Of note, the comparative analysis of the portfolios for both scenarios showed a $53 \%$ coincidence in the included projects.

In addition, the value of the integrated index would be higher by 0.11 points when using the project portfolio formed under the proposed model. Thus, we can talk about increasing the effectiveness when planning a project portfolio using the proprietary optimization model.

In conducting a comparative analysis of the use of the crisp and fuzzy models in the optimization scenario, we noted that the similarity of the portfolios was $92 \%$. This occurred because the fuzzy approach takes into account the boundary values of the fuzzy number, which is not possible for the crisp model.

We should also emphasize the practical relevance of this study because it provides a tool that allows for the improvement of the efficiency of the decision-making by regional authorities in terms of the inclusion in the regional budget of costs for the implementation of certain strategic projects by taking into account their scarcity and task set.

\section{Conclusions}

The fuzzy economic and mathematical model has been developed, which allows the formation of an optimal portfolio of regional strategic projects that directly or indirectly affect the development of regional human capital. The objective function of the model is an integrated index that characterizes the degrees of achievement of the targets of social and economic development of the region for a given planning period. The variables used for optimization are the Boolean variables of the inclusion of a project in a particular investment area at a certain point in time.

In comparison with previous studies, a distinctive feature of this model is the consideration of two levels of uncertainty in the formation of an optimal portfolio of regional strategic projects. The first level is associated with the reliability of estimates of numerical coefficients of dependencies (Equation 2) and (Equation 3). The second level is associated with the need to set a number of parameters for dependencies (Equation 5) and (Equation 6) and restrictions (Equation 10) through (Equation 12), which are determined by the experts. To model these uncertainties, a fuzzy-multiple approach is used, and the developed model is a fuzzy mathematical programming problem.

This study proposes a method to identify a solution for the fuzzy problem of forming an optimal portfolio of regional strategic projects. The idea of the approach is to reduce the fuzzy optimization model to a crisp one by converting fuzzy inequalities for the objective function and restrictions into crisp ones at given confidence levels.

The formation of the optimal portfolio of strategic projects for the Primorsky Region considers the computation aspects of the proposed model. The resulting structure of the regional budget investments by investment areas is formed on the basis of a pool of strategic projects. A comparative analysis of the investment structure resulting from the use of the model and reflected in the draft regional budget was performed. The analysis showed a higher efficiency of financial resources expressed in a greater degree of achieving the integrated index and the targets of social and economic development for the regional project portfolio formed on the basis of the proposed model. 


\section{Acknowledgements}

The study was sponsored by the Russian Foundation for Basic Research (RFBR) as part of research project No. 18-010-01010.

\section{References}

Anshin, V.M., 2015. Methodological Aspects of Measuring Mutual Effect of Project Portfolio and Company's Goals. Russian Journal of Project Management, Volume 4(3), pp. 3-8

Aras, A.C., Kaynak, O., Batyrshin, I., 2008. A Comparison of Fuzzy Methods for Modeling. In: Proc. of $34^{\text {th }}$ Annual Conference of the IEEE Industrial Electronics Society (IECON 2008), pp. 4348

Berawi, M.A., 2019. The Role of Industry 4.0 in Achieving Sustainable Development Goals. International Journal of Technology, Volume 10(4), pp. 644-647

Berawi, M.A., 2020. Empowering Healthcare, Economic, and Social Resilience during Global Pandemic COVID-19. International Journal of Technology, Volume 11(3), pp. 436-439

Carlsson, C., Fuller, R., Heikkila, M., Majlender, P., 2007. A Fuzzy Approach to R\&D Project Portfolio Selection. International Journal of Approximate Reasoning, Volume 44(2), pp. 93-105

Christian, M.S., 2014. Human Capital Accounting in the United States: Context, Measurement, and Application. In: Measuring Economic Sustainability and Progress (Studies in Income and Wealth, Volume 72), Jorgenson, D.W., Landefeld, J.S., Schreyer, P. (Eds.). National Bureau of Economic Research, New York, NY, USA, pp. 461-491

Fraumeni, B.M., He, J., Li, H., Liu, Q., 2019. Regional Distribution and Dynamics of Human Capital in China 1985-2014. Journal of Comparative Economics, Volume 47(4), pp. 853866

Gurban, I.A., 2015. The Regional Ranking of Human Capital Development in Russia. REconomy. Volume 1(4), pp. 563-572

Li, H., He, J., Liu, Q., Fraumeni, B.M., Zheng, X., 2016. Regional Distribution and Dynamics of Human Capital in China 1985-2014: Education, Urbanization, and Aging of the Population. Working Paper 22906, National Bureau of Economic Research, Cambridge, MA, USA. Available Online at https://www.nber.org/papers/w22906.pdf

Lim, S.S., Updike, R.L., Kaldjian, A.S., Barber, R.M., Cowling, K., York, H., Friedman, J., Xu, R., Whisnant, J.L., Taylor, H.J., Leever, A.T., Roman, Y., Bryant, M.F., Dieleman, J., Gakidou, E., Murray, C.J.L., 2018. Measuring Human Capital: A Systematic Analysis of 195 Countries and Territories, 1990-2016. The Lancet, Volume 392(10154), pp. 12171234

Mazelis, L., Lavrenyuk, K., Krasko, A., Krasova, E., Emtseva, E., 2020. Devising a Method to Optimize the Investment Structure Aimed to Achieve Strategic Targets in the SocioEconomic Development of Regions. Eastern-European Journal of Enterprise Technologies, Volume 1(3), pp. 12-24

Mazelis, L.S., Lavrenyuk, K.I., Krasko, A.A., Zagudaeva, O.N., 2018. A Conceptual Model of the Regional Human Capital Development. International Transaction Journal of Engineering, Management and Applied Sciences and Technologies, Volume 9(5), pp. 477-494

McDonald, B.D., 2019. A Human Capital Model of the Defense-growth Relationship. The Social Science Journal. Available online at https://www.tandfonline.com/doi/abs/10.1016/j.soscij.2019.04.005, doi: 10.1016/j.soscij.2019.04.005

Olopade, B.C., Okodua, H., Oladosun, M., Asaleye, A.J., 2019. Human Capital and Poverty Reduction in OPEC Member-Countries. Heliyon, Volume 5(8), pp. 1-7 
Pelinescu, E., 2014. The Impact of Human Capital on Economic Growth. In: Second International Conference "Economic Scientific Research-Theoretical, Empirical and Practical Approaches," Bucharest, Romania, pp. 184-190

Percoco, M., 2016. Health Shocks and Human Capital Accumulation: The Case of Spanish Flu in Italian Regions. Regional Studies, Volume 50(9), pp. 1496-1508

Santoso, H., Bramantoro Abdinagoro, S., Arief, M., 2019. The Role of Digital Literacy in Supporting Performance Through Innovative Work Behavior: The Case of Indonesia's Telecommunications Industry. International Journal of Technology, Volume 10(8), pp. 1558-1566

Soubjaki, M., 2017. Challenges Facing Human Capital Return on Investment (HCROI) in Mena Region. Journal of Business and Management, Volume 19(11), pp. 82-88

Teixeira, A.A.C., Queirós, A.S.S., 2016. Economic Growth, Human Capital and Structural Change: A Dynamic Panel Data Analysis. Research Policy, Volume 45(8), pp. 1636-1648

United Nations Development Programme (UNDP), 2019. Human Development Report 2019. UNDP, New York, NY, USA

Wang, J., Hwang, W.-L., 2007. A Fuzzy Set Approach for R\&D Portfolio Selection using a Real Option Valuation Model. Omega, Volume 35(3), pp. 247-257

Zallé, O., 2019. Natural Resources and Economic Growth in Africa: The Role of Institutional Quality and Human Capital. Resources Policy, Volume 62, pp. 616-624 